OPEN ACCESS

Edited by:

Adam Bush,

Stanford University, United States

Reviewed by:

Joseph Arnold Fisher,

University Health Network (UHN),

Canada

Jan Petr,

Helmholtz Center

Dresden-Rossendorf, Helmholtz

Association of German Research

Centres (HZ), Germany

Aart Nederveen,

University of Amsterdam, Netherlands

*Correspondence:

Eboni Lance

lance@kennedykrieger.org

Specialty section:

This article was submitted to Red Blood Cell Physiology,

a section of the journal

Frontiers in Physiology

Received: 14 November 2021

Accepted: 21 January 2022

Published: 11 February 2022

Citation:

Lin Z, Mclntyre T, Jiang $D$, Cannon A, Liu P, Tekes A, Casella JF,

Slifer K, Lu H and Lance E (2022)

Brain Oxygen Extraction and Metabolism in Pediatric Patients With Sickle Cell Disease: Comparison

of Four Calibration Models.

Front. Physiol. 13:814979.

doi: 10.3389/fphys.2022.814979

\section{Brain Oxygen Extraction and Metabolism in Pediatric Patients With Sickle Cell Disease: Comparison of Four Calibration Models}

Zixuan Lin', Tiffany McIntyre ${ }^{2}$, Dengrong Jiang ${ }^{1}$, Alicia Cannon ${ }^{3}$, Peiying Liu', Aylin Tekes ${ }^{1}$, James F. Casella ${ }^{4}$, Keith Slifer ${ }^{5,6}$, Hanzhang Lu ${ }^{1,7}$ and Eboni Lance ${ }^{2,8 *}$

\begin{abstract}
${ }^{1}$ The Russell H. Morgan Department of Radiology and Radiological Science, The Johns Hopkins University School of Medicine, Baltimore, MD, United States, ${ }^{2}$ Department of Neurology and Developmental Medicine, Kennedy Krieger Institute, Baltimore, MD, United States, ${ }^{3}$ Department of Neuropsychology, Kennedy Krieger Institute, Baltimore, MD, United States, ${ }^{4}$ Division of Pediatric Hematology, Department of Pediatrics, The Johns Hopkins University School of Medicine, Baltimore, MD, United States, ${ }^{5}$ Department of Behavioral Psychology, Kennedy Krieger Institute, Baltimore, MD, United States, ${ }^{6}$ Department of Psychiatry and Behavioral Sciences, The Johns Hopkins University School of Medicine, Baltimore, MD, United States, ${ }^{7}$ F. M. Kirby Research Center for Functional Brain Imaging, Kennedy Krieger Institute, Baltimore, MD, United States, ${ }^{8}$ Department of Neurology, The Johns Hopkins University School of Medicine, Baltimore, MD, United States
\end{abstract}

Sickle cell disease (SCD) is an inherited hemoglobinopathy with an increased risk of neurological complications. Due to anemia and other factors related to the underlying hemoglobinopathy, cerebral blood flow (CBF) increases as compensation; however, the nature of alterations in oxygen extraction fraction (OEF) and cerebral metabolic rate of oxygen $\left(\mathrm{CMRO}_{2}\right)$ in SCD remains controversial, largely attributed to the different calibration models. In addition, limited studies have been done to investigate oxygen metabolism in pediatric patients. Thus, this study used a non-invasive $T_{2}$-based MR oximetry, $\mathrm{T}_{2}$-Relaxation-Under-Spin-Tagging (TRUST) MRI, to measure oxygen homeostasis in pediatric patients with SCD using four different calibration models and examined its relationship to hematological measures. It was found that, compared with controls, SCD patients showed an increased CBF, unchanged total oxygen delivery and increased venous blood $\mathrm{T}_{2}$. The results of $\mathrm{OEF}$ and $\mathrm{CMRO}_{2}$ were dependent on the calibration models used. When using sickle-specific, hemoglobin $\mathrm{S}(\mathrm{HbS})$ leveldependent calibration, there was a decreased OEF and $\mathrm{CMRO}_{2}$, while the bovine model showed an opposite result. OEF and $\mathrm{CMRO}_{2}$ were also associated with hemoglobin and $\mathrm{HbS}$ level; the direction of the relationship was again dependent on the model. Future studies with in vivo calibration are needed to provide more accurate information on the $\mathrm{T}_{2}-\mathrm{Y}_{v}$ relationship.

Keywords: sickle cell disease, OEF, CMRO 2 , CBF, TRUST MRI 


\section{INTRODUCTION}

Sickle cell disease (SCD) is an inherited blood disorder, in which a beta globin gene mutation causes the formation of a mutated protein, hemoglobin $\mathrm{S}(\mathrm{HbS})$, leading to the deformation of red blood cell (RBC) into a sickled shape. This also leads to hemolysis and decreased hemoglobin, thus decreased arterial oxygen content, resulting in an elevated cerebral blood flow (CBF) in order to compensate for the oxygen demand of the brain (Herold et al., 1986; Hurlet-Jensen et al., 1994a; Li et al., 2020). SCD has been associated with a number of brain physiological disorders, including increased cerebral vasculopathy, reduced cerebrovascular reactivity, and increased risk of overt stroke or silent cerebral infarction (SCI) (Pauling et al., 1949; Hurlet-Jensen et al., 1994b; Miller et al., 2001; Prengler et al., 2002; Switzer et al., 2006; Leung et al., 2016; Juttukonda et al., 2017; Bush et al., 2018a; Jordan and DeBaun, 2018; Václavů et al., 2019; Jacob et al., 2020; Kirkham and Lagunju, 2021; Stotesbury et al., 2021). An increased risk of neurodevelopmental disorders in pediatric SCD patients was also reported (Berkelhammer et al., 2007; Lance et al., 2015, 2021).

One potential physiological biomarker in SCD is the oxygen extraction fraction (OEF). Due to the lack of oxygen carrying capacity of the sickled blood cell, the OEF may increase as a compensation; however, when the $\mathrm{CBF}$ and flow velocity increase, the OEF may also decrease due to insufficient diffusion time (Juttukonda et al., 2020) or excessive blood flow (Bush et al., 2018b) in arteriovenous shunting. Meanwhile, cerebral metabolic rate of oxygen $\left(\mathrm{CMRO}_{2}\right)$, which represents the oxidative metabolism of the brain, may also be altered. Additionally, increased OEF has been associated with increased risk of stroke in certain regions of the brain (Fields et al., 2018). Chronic blood transfusion, a disease modifying treatment for SCD, is associated with lower CBF and OEF (Guilliams et al., 2018).

The gold standard to measure the OEF and $\mathrm{CMRO}_{2}$ is ${ }^{15} \mathrm{O}$ PET, which is highly invasive and requires onsite production of ${ }^{15} \mathrm{O}$ isotope. Herold et al. (1986) using ${ }^{15} \mathrm{O}$-PET reported no significant differences in OEF $(42 \pm 4 \%$ for control and $44 \pm 7 \%$ for SCD) or $\mathrm{CMRO}_{2}$ between SCD and control groups, while Heyman et al. (1952) using a nitrous oxide method showed moderately reduced arteriovenous oxygen difference and $\mathrm{CMRO}_{2}$ in SCD. Recently, several MRI-based techniques have been developed to measure OEF non-invasively. One is $\mathrm{T}_{2}$-based oximetry, based on the principle that oxygen content in the blood can alter the blood $\mathrm{T}_{2}$ due to its magnetic property (Wright et al., 1991; Silvennoinen et al., 2003; Zhao et al., 2007; Lu and Ge, 2008; Lu et al., 2012). Several studies have been conducted in SCD patients to investigate the role of OEF and $\mathrm{CMRO}_{2}$ using the $\mathrm{T}_{2}$-based method (Jordan et al., 2016; Bush et al., 2018b, 2021; Morris et al., 2018; Vaclavu et al., 2018; Juttukonda et al., 2019, 2020; Li et al., 2020; Václavi̊ et al., 2020; Prussien et al., 2021; Vu et al., 2021); however, the results of these studies are variable, largely due to the calibration models used to convert venous blood $\mathrm{T}_{2}$ to venous oxygenation $\left(\mathrm{Y}_{v}\right)$. Using a bovine blood model, Jordan et al. (2016) reported increased OEF and $\mathrm{CMRO}_{2}$ in SCD; however, it has been speculated that the bovine model may not be suitable for sickled blood, due to a much lower hematocrit range and different size, shape, and permeability of the sickled blood cell (Clark and Rossi, 1990; Gibson and Ellory, 2002). Thus, Bush et al. (2018b) reported a HbS calibration model which showed a decreased OEF and $\mathrm{CMRO}_{2}$ in SCD. However, the Bush model has no hematocrit dependence and omitted the linear term in the equation, yielding an OEF value approximately half of the results from the PET study. In addition, Li et al. (2020) presented an individual calibration model and reported no change in OEF and $\mathrm{CMRO}_{2}$ in SCD. In order to establish a unified model for sickled blood, Li's group and Bush's group combined their data and proposed a Li-Bush sickle-specific calibration model (Bush et al., 2021).

No studies have been done to compare all these four models in one cohort. In addition, the majority of the $\mathrm{T}_{2}$-based studies mentioned above were conducted in adult SCD patients. The oxygen metabolism in pediatric patients may be different than in adults. Thus, in this study, we aimed to investigate the oxygen homeostasis in a group of pediatric SCD participants, using $\mathrm{T}_{2}$-Relaxation-Under-Spin-Tagging (TRUST) MRI (Lu and Ge, 2008; Lu et al., 2012; Xu et al., 2012; Jiang et al., 2018). Results from all four available $T_{2}-Y_{v}$ calibration models were compared. Difference in oxygen homeostasis between SCD participants and age-matched controls were examined. The relationships between oxygen homeostasis and different SCD phenotypes, hematological measures, silent cerebral infarction and neuropsychological performance were also examined.

\section{MATERIALS AND METHODS}

\section{Participants}

The Institutional Review Board (IRB) of Johns Hopkins University approved the study and the guardians of the participants signed IRB-approved consent forms before enrolling in the study. A total of 28 pediatric participants were recruited $(10.0 \pm 1.3$ years, $12 \mathrm{M} / 16 \mathrm{~F})$, including 21 SCD participants and seven controls. The inclusion criteria for SCD participants was 8-12 years of age with diagnosis of SCD validated by lab testing or confirmed by hematologist. Participants with any prior history of stroke, silent cerebral infarction or seizures, participants who need an interpreter, and participants who were adopted or in foster care were excluded. Study recruitment of sickle cell disease patients was done through local pediatric hematology clinics. Siblings of SCD participants were recruited as control participants. Additional control participants were recruited through internet postings, flyers, and email. The study recruitment started from May 2018 and ended in June 2021. Among SCD participants, 11 had hemoglobin SS, one had hemoglobin $S \beta^{0}$ thalassemia, three had hemoglobin $S \beta^{+}$ thalassemia and six had hemoglobin SC. Fourteen of the SCD participants were on hydroxyurea treatment in the past but not at the time of study. Among the seven controls, four were siblings of SCD patients and had sickle cell trait ( $\mathrm{HbS}$ fraction range from 31.9 to $39.2 \%$, median $33.1 \%$ ). 8 out of the 21 SCD participants had abnormal MRI findings, including six with SCI, one with few scattered white matter hyperintensities and one with hypothalamic/thalamic mass. 


\section{Hematological Assessment}

Blood samples were obtained for all participants on the day of the MRI. Concentration of hematocrit, hemoglobin and reticulocytes were determined for all participants. Fraction of $\mathrm{HbS}$ was measured for all SCD participants and a subset of three controls with sickle cell trait. One trait participant has $\mathrm{HbAC}$ trait, thus no $\mathrm{HbS}$ value.

\section{MRI Experiments}

All participants were studied on a 3T Philips Ingenia System (Philips Healthcare, Best, Netherlands).

$\mathrm{T}_{2}$-Relaxation-Under-Spin-Tagging $\mathrm{MRI}$ was performed for the measurement of OEF by isolating the venous blood signal with venous spin labeling, followed by a series of $\mathrm{T}_{2}$ preparation pulses ( $\mathrm{Lu}$ and $\mathrm{Ge}, 2008$; Xu et al., 2012; Figure 1A). The imaging parameters were as follows: $\mathrm{TR}=3,000 \mathrm{~ms}, \mathrm{TE}=3.61 \mathrm{~ms}$, inversion time $(\mathrm{TI})=1022 \mathrm{~ms}$, flip angle $=90^{\circ}, \mathrm{FOV}=220 \mathrm{~mm} \times 220 \mathrm{~mm} \times 5 \mathrm{~mm}$, voxel size $=3.44 \mathrm{~mm} \times 3.44 \mathrm{~mm} \times 5 \mathrm{~mm}$, four eTEs $(0,40,80$, and $160 \mathrm{~ms}$ ) with a $\tau$ CPMG of $10 \mathrm{~ms}$, labeling thickness $=100 \mathrm{~mm}$, and scan duration $=1.2 \mathrm{~min}$.

Phase-contrast (PC) MRI was then performed to measure the global CBF (Peng et al., 2014, 2015). An angiogram was first conducted at the cervical region to visualize the four feeding arteries (left and right internal carotid arteries, left and right vertebral arteries), with the following parameters: $\mathrm{TR}=26 \mathrm{~ms}, \mathrm{TE}=5.8 \mathrm{~ms}$, flip angle $=20^{\circ}, \mathrm{FOV}=200 \mathrm{~mm} \times 200 \mathrm{~mm} \times 80 \mathrm{~mm}$, voxel size $=0.5 \mathrm{~mm} \times 0.99 \mathrm{~mm} \times 2 \mathrm{~mm}$, number of slices $=40$, and scan duration $=1 \mathrm{~min} 39 \mathrm{~s}$. PC MRI was acquired for each of the arteries with the imaging plane perpendicular to the targeting artery. The imaging parameters were as follows: $\mathrm{TR}=18.9 \mathrm{~ms}$, $\mathrm{TE}=9.3 \mathrm{~ms}$, flip angle $=15^{\circ}, \mathrm{FOV}=200 \mathrm{~mm} \times 200 \mathrm{~mm} \times 5 \mathrm{~mm}$, voxel size $=0.5 \mathrm{~mm} \times 0.5 \mathrm{~mm} \times 5 \mathrm{~mm}$, single slice, encoding velocity $\left(\mathrm{V}_{\text {enc }}=40 \mathrm{~cm} / \mathrm{s}\right)$, and scan duration $=15 \mathrm{~s}$.

A $\mathrm{T}_{1}$-weighted magnetization-prepared-rapid-acquisition-ofgradient-echo (MPRAGE) scan was acquired for brain volume quantification with the following parameters: radial acquisition, $\mathrm{TR}=7.2 \mathrm{~ms}, \mathrm{TE}=3.1 \mathrm{~ms}$, shot interval $=2,150 \mathrm{~ms}, \mathrm{TI}=1,100 \mathrm{~ms}$, flip angle $=10^{\circ}, \mathrm{FOV}=224 \mathrm{~mm} \times 224 \mathrm{~mm} \times 160 \mathrm{~mm}$, voxel size $=1 \mathrm{~mm} \times 1 \mathrm{~mm} \times 1 \mathrm{~mm}$, number of slices $=160$, sagittal orientation, and scan duration $=2 \min 28 \mathrm{~s}$.

\section{MRI Data Processing}

To obtain OEF, subtraction between TRUST control and label images yields pure venous blood signals. Region of interest (ROI) containing the SSS were drawn manually on the difference images and the four voxels with maximum signal intensity were chosen. Venous blood $\mathrm{T}_{2}$ was quantified by fitting the signals at different effective echo times to a mono-exponential model (Figure 1B). Blood $\mathrm{T}_{2}$ was then converted to $\mathrm{Y}_{v}$ using four available calibration models:

(1) A bovine model (Lu et al., 2012).

$$
\frac{1}{T_{2}}=A+B \cdot(1-Y)+C \cdot(1-Y)^{2}
$$

Where $A=-13.5+80.2 \cdot H c t-75.9 \cdot H_{c} t^{2}, \quad B=0.5$. $\mathrm{Hct}+3.4 \cdot \mathrm{Hct}^{2}$, and $\mathrm{C}=247.4 \cdot \mathrm{Hct} \cdot(1-\mathrm{Hct})$.

(2) A sickle human blood model calibrated with HbS blood (Bush model) (Bush et al., 2018b).

$$
\frac{1}{T_{2}}=A \cdot(1-Y)^{2}+B
$$

Where $A=70$ and $B=5.75$.

(3) A sickle blood model calculated based on individual calibration (Li model) (Li et al., 2020) (detailed parameters was obtained from the authors through personal communication).

$$
\frac{1}{T_{2}}=A+B \cdot(1-Y)+C \cdot(1-Y)^{2}
$$

Where $\quad A=21.7-108.5 \cdot H c t+189.5 \cdot H_{c t}{ }^{2}$, $B=56.2 \cdot H c t-73.1 \cdot H_{c t}{ }^{2}, \quad$ and $\quad C=242.5 \cdot H c t$. $(1-H c t)$.

(4) A joint model calculated based on the datasets from the previous two studies (Li-Bush model) (Bush et al., 2021).

$$
\frac{1}{T_{2}}=A \cdot(1-Y)^{2}+B
$$

Where $A=196.8 \cdot H c t+16.7$ and $B=-6.6 \cdot H c t+8.6$.

For the last three models, to account for subject-specific HbS level, the respective sickled blood model and normal human blood model (as stated in each of these studies) were first interpolated to obtain a $\mathrm{Hb}$-specific calibration curve, i.e., a linear mixture of the $\mathrm{HbS}$ and normal human blood calibration weighted by individual $\mathrm{HbS}$ level, from which $\mathrm{Y}_{v}$ was estimated. OEF was calculated using the following equation:

$$
O E F=\left(Y_{a}-Y_{v}\right) / Y_{a}
$$

Where $\mathrm{Y}_{a}$ is arterial oxygenation (assumed to be $98 \%$ ).

For PC-MRI, ROIs were drawn manually for the left/right internal carotid arteries and left/right vertebral arteries. The total flux of the arteries were calculated by the sum of the velocity in the ROI (Peng et al., 2015). Aliasing correction was done when the maximum velocity exceeded the VENC. The $\mathrm{T}_{1}$-MPRAGE images were segmented using an automatic processing tool, MRICloud (Mori et al., 2016) (Johns Hopkins University, Baltimore, MD, United States) ${ }^{1}$ for brain volume quantification. Then the global $\mathrm{CBF}$ was quantified by normalizing the total flux with the total brain parenchymal volume.

The oxygen delivery rate $\mathrm{DO}_{2}(\mu \mathrm{mol} / 100 \mathrm{~g} / \mathrm{min})$ was calculated based on individual hematocrit level:

$$
\mathrm{DO}_{2}=\mathrm{CBF} \cdot \mathrm{Ch} \cdot \mathrm{Y}_{a}
$$

Where $\mathrm{Ch}$ is amount of oxygen that a unit of volume of blood can carry and is $\mathrm{Hb}$ dependent. In this study, it was assumed to be $\mathrm{Ch}=20.4^{*}$ hematocrit, based on previous literature

${ }^{1}$ www.MRICloud.org 
A

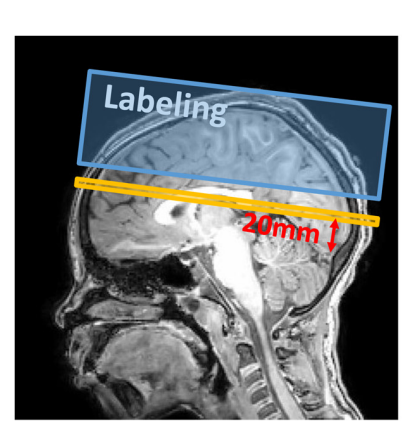

B

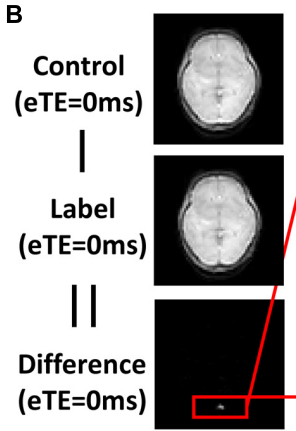

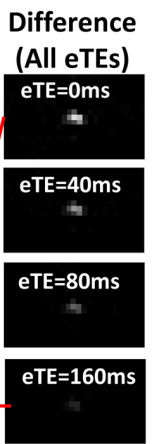

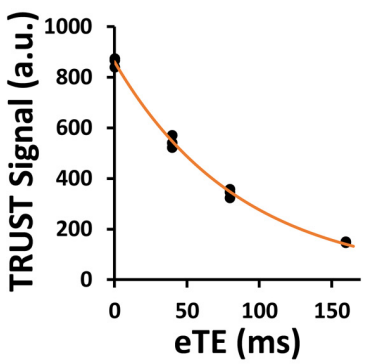

FIGURE 1 | Representative results of $\mathrm{T}_{2}$-Relaxation-Under-Spin-Tagging (TRUST) MRI. (A) Position of image plane for TRUST MRI. Yellow bar indicates the imaging slice. Blue box indicates the labeling slab. (B) Representative images of TRUST MRI for quantification of venous blood $T_{2}$. Paired subtraction between control and label images results in a different image, in which the superior sagittal sinus (red box) is prominent. Fitting of the signal as a function of eTE results in the estimation of venous blood $\mathrm{T}_{2}$.

(Guyton and Hall, 2005). $\mathrm{CMRO}_{2}$ was also calculated based on Fick Principle (Kety and Schmidt, 1948):

$$
C M R O_{2}=C B F \cdot\left(Y_{a}-Y_{v}\right) \cdot C h
$$

\section{Statistical Analysis}

Age and education were compared between SCD participants and control participants by Wilcoxon rank sum test. Sex was compared between groups using Chi-square test. Group difference in hematological measures, brain volume and cognitive performance were examined using linear regression analysis, with age, sex, and education as covariates when relevant.

Cerebral physiological parameters, including $\mathrm{CBF}, \mathrm{DO}_{2}$, $\mathrm{OEF}$, and $\mathrm{CMRO}_{2}$ were compared between the SCD and control groups using linear regression analysis, where the physiological parameter was the dependent variable and group index was the independent variable, with age and sex as covariates. Considering that some of the control participants also had sickle cell trait, we further split the control subjects into two sub-groups and the above-mentioned parameters were compared between controls with trait and controls without trait.

To determine if the choice of the model affects the relative group differences or only the absolute values, relative change in $\mathrm{OEF}$ and $\mathrm{CMRO}_{2}$ was calculated as the percentage change in SCD compared to the average value in the control group. Then a Kruskal-Wallis test was used to compare the values among different models.

The association between the cerebral physiological parameters and the hematological measures were evaluated in the entire cohort using linear regression with the physiological parameter as the dependent variable, hematological parameter (i.e., hemoglobin, reticulocytes, or $\mathrm{HbS}$ ) as the independent variable, age and sex as the covariates. Similar analysis was done within the SCD group as well.

In all analyses, a two-tailed p-value of 0.05 or less was considered statistically significant.

\section{RESULTS}

\section{Demographics and Hematological Measures}

The demographic information for all participants were summarized in Table 1 . There were no significant differences in age $(p=0.68)$, sex $(p=0.27)$ and education $(p=0.15)$ between the SCD and control groups. After controlling for age and sex, there were no differences in the brain volumes between two groups, including whole brain $(p=0.95)$, frontal lobe $(p=0.16)$, parietal lobe $(p=0.13)$, temporal lobe $(p=0.36)$ and occipital lobe $(p=0.63)$.

After controlling for age and sex in regression analysis, SCD patients had lower hematocrit (SCD: $26.7 \pm 5.4 \%$, control: $37.7 \pm 1.9 \%, p<0.0001$ ), lower hemoglobin (SCD: $9.3 \pm 2.0 \mathrm{gm} / \mathrm{dL}$, control: $12.8 \pm 0.8 \mathrm{gm} / \mathrm{dL}, p=0.00027)$ and higher HbS fraction (SCD: $65.9 \pm 16.9 \%$, control: $15.7 \pm 19.8 \%$, $p=0.00074)$ than the control group.

TABLE 1 | Demographics information of SCD patients and control participants (mean $\pm \mathrm{SD})$.

\begin{tabular}{|c|c|c|c|}
\hline & SCD & Control & $p$-value \\
\hline N & 21 & 7 & \\
\hline Age, years & $9.9 \pm 1.2$ & $10.1 \pm 1.7$ & 0.68 \\
\hline Females, $N(\%)$ & $11(52 \%)$ & $5(71 \%)$ & 0.27 \\
\hline Education, years & $3.5 \pm 1.3$ & $4.4 \pm 2.4$ & 0.15 \\
\hline Hematocrit (\%) & $26.67 \pm 5.4$ & $37.69 \pm 1.9$ & $<0.0001$ \\
\hline Hemoglobin (g/dL) & $9.3 \pm 2.0$ & $12.8 \pm 0.8$ & 0.00027 \\
\hline $\mathrm{HbS}(\%)$ & $65.9 \pm 16.9$ & $15.7 \pm 19.8$ & 0.00074 \\
\hline Reticulocyte (\%) & $6.36 \pm 4.58$ & $1.16 \pm 0.42$ & 0.024 \\
\hline $\mathrm{CBF}(\mathrm{mL} / 100 \mathrm{~g} / \mathrm{min})$ & $118.9 \pm 27.7$ & $73.0 \pm 10.0$ & 0.00043 \\
\hline$N$ on hydroxyurea in the past & 15 & & \\
\hline$N$ receive blood transfusion & 0 & & \\
\hline \multirow[t]{4}{*}{$N$ for different SCD phenotypes } & $11 \mathrm{HbSS}$ & & \\
\hline & $1 \mathrm{HbS} \beta^{0}$ & & \\
\hline & $3 \mathrm{HbS}^{+}$ & & \\
\hline & $6 \mathrm{Hb} \mathrm{SC}$ & & \\
\hline
\end{tabular}




\section{Cerebral Physiological Difference Between Sickle Cell Disease and Controls}

Sickle cell disease participants had a significantly higher venous $\mathrm{T}_{2}$ compared with control participants (SCD: $91.2 \pm 13.4 \mathrm{~ms}$, control: $72.0 \pm 9.6 \mathrm{~ms}, p=0.0033$, Table 2). Figures 2A,B showed the boxplots of $\mathrm{CBF}$ and $\mathrm{DO}_{2}$, respectively, in the SCD and control groups. Compared with control participants, SCD participants had a significantly higher CBF (SCD: $118.7 \pm 27.7 \mathrm{~mL} / 100 \mathrm{~g} / \mathrm{min}$, control: $73.0 \pm 10.0 \mathrm{~mL} / 100 \mathrm{~g} / \mathrm{min}, p=0.00043)$, but the total oxygen delivery $\mathrm{DO}_{2}$ was not significantly different between two groups (SCD: $612.3 \pm 103.3 \mu \mathrm{mol} / 100 \mathrm{~g} / \mathrm{min}$, control: $549.5 \pm 76.6 \mu \mathrm{mol} / 100 \mathrm{~g} / \mathrm{min}, p=0.15)$.

Figures 2C,D and Table 2 show $\mathrm{OEF}$ and $\mathrm{CMRO}_{2}$ when calibrated using different models. When using the Li-Bush model, SCD patients showed a significantly decreased OEF $(p=0.00027)$ and $\mathrm{CMRO}_{2}(p=0.0099)$ compared with control participants. When using the Bush model, there was also a decrease in OEF $(p<0.0001)$ and $\mathrm{CMRO}_{2}(p=0.0097)$ in SCD participants. Similar differences were found when using the Li-model (OEF: $\left.p=0.0017 ; \mathrm{CMRO}_{2}: p=0.028\right)$. But there were no significant differences in the relative change of OEF or $\mathrm{CMRO}_{2}$ in SCD compared to control group among these three models. In contrast, when using the bovine model, OEF showed an opposite result, i.e., a trend of increase in SCD participants compared with controls $(p=0.059)$, and $\mathrm{CMRO}_{2}$ were increased as well $(p=0.0073)$.

When dividing the controls into sickle cell S/C-trait and nonsickle cell S/C-trait participants, all four models showed that the trait participants had a lower mean $\mathrm{CMRO}_{2}$ compared with nontrait participants (Figure 3 and Table 2).

\section{Relationships Between Cerebral Physiology and Hematological Measures}

Table 3 showed the linear regression results between cerebral physiology and hematological measures. Linear regression analysis showed that the participants with lower hemoglobin had a significant higher CBF $(\beta=-10.83,95 \%$ CI $[-13.95$,
-7.71], $p<0.0001)$ and a higher venous blood $\mathrm{T}_{2}(\beta=-4.25$, 95\% CI $[-6.28,-2.23], p=0.00023$ ) (Figure 4). Results from the Bush model, Li model and Li-Bush model all indicated that lower hemoglobin level was associated with lower OEF and lower $\mathrm{CMRO}_{2}$ (Figure 5). However, the bovine model showed an opposite result, i.e., lower hemoglobin level was associated with higher $\mathrm{OEF}$ and higher $\mathrm{CMRO}_{2}$. There was no significant relationship between $\mathrm{DO}_{2}$ and hemoglobin level.

It was also found that participants with a higher $\mathrm{HbS}$ fraction had a higher CBF $(\beta=1.06,95 \%$ CI $[0.68,1.44], p<0.0001)$ and higher venous $\mathrm{T}_{2}(\beta=0.33,95 \%$ CI $[0.079,0.58], p=0.00079)$. When using the Bush model, Li-model or the Li-Bush model, participants with a higher $\mathrm{HbS}$ fraction showed a significant lower OEF and lower $\mathrm{CMRO}_{2}$. However, results from the bovine model showed an opposite result.

In addition, higher reticulocytes level was associated with higher CBF $(\beta=3.68,95 \%$ CI $[1.39,5.98], p=0.0031)$ and a trend of higher venous blood $\mathrm{T}_{2}(\beta=1.18,95 \% \mathrm{CI}[-0.11,2.47]$, $p=0.070$ ). Results from the Bush model, Li model, and Li-Bush model all showed that participants with a higher reticulocytes count had a lower OEF and higher $\mathrm{CMRO}_{2}$, while the bovine model showed an opposite result. There was also no significant association between $\mathrm{DO}_{2}$ and reticulocytes level.

Similar analysis was done within the SCD patients only, and the results are largely consistent with the above findings in that entire cohort (Table 4).

\section{DISCUSSION}

In this study, we investigated brain physiological parameters in pediatric sickle cell patients. We found that CBF is higher in SCD patients and this compensatory response appears to be sufficient in offsetting a reduced hemoglobin concentration, because total oxygen delivery, $\mathrm{DO}_{2}$, was not different from controls. In terms of $\mathrm{OEF}$ and $\mathrm{CMRO}_{2}$, the present study conducted a comprehensive investigation of four different calibration models and found that the results are dependent on model used. When using sicklespecific calibration (Li-Bush model, Bush model, and Li model), there was a decreased $\mathrm{OEF}$ and $\mathrm{CMRO}_{2}$ in SCD participants

TABLE 2 | Comparison of cerebral physiological parameters among different diagnostic groups.

\begin{tabular}{|c|c|c|c|c|c|c|}
\hline & SCD & All controls & Controls: Trait & Controls: Non-trait & $\begin{array}{c}p \text {-value between } \\
\text { SCD and all controls }\end{array}$ & $\begin{array}{c}p \text {-value between trait } \\
\text { and non-trait }\end{array}$ \\
\hline$N$ & 21 & 7 & 4 & 3 & & \\
\hline $\mathrm{CBF}(\mathrm{mL} / 100 \mathrm{~g} / \mathrm{min})$ & $118.7 \pm 27.7$ & $73.0 \pm 10.0$ & $69.1 \pm 10.9$ & $78.4 \pm 7.0$ & 0.00043 & 0.34 \\
\hline $\mathrm{DO}_{2}(\mathrm{~mL} / 100 \mathrm{~g} / \mathrm{min})$ & $612.3 \pm 103.3$ & $549.5 \pm 76.6$ & $508.5 \pm 74.8$ & $604.3 \pm 36.8$ & 0.15 & 0.22 \\
\hline $\mathrm{T}_{2}(\mathrm{~ms})$ & $91.2 \pm 13.4$ & $72.0 \pm 9.6$ & $74.1 \pm 10.6$ & $69.3 \pm 9.4$ & 0.0033 & 0.56 \\
\hline OEF-Li-Bush (\%) & $24.8 \pm 6.1$ & $36.2 \pm 4.6$ & $33.8 \pm 4.0$ & $39.4 \pm 3.8$ & 0.00027 & 0.22 \\
\hline OEF-Bush (\%) & $25.9 \pm 5.4$ & $37.2 \pm 4.0$ & $35.6 \pm 3.8$ & $39.4 \pm 3.7$ & $<0.0001$ & 0.35 \\
\hline OEF-Li (\%) & $22.5 \pm 6.7$ & $32.8 \pm 4.5$ & $30.7 \pm 4.2$ & $35.7 \pm 3.6$ & 0.0017 & 0.28 \\
\hline OEF-Bovine (\%) & $41.8 \pm 7.9$ & $35.5 \pm 3.4$ & $35.1 \pm 3.7$ & $35.9 \pm 3.7$ & 0.059 & 0.77 \\
\hline $\mathrm{CMRO}_{2}$-Li-Bush ( $\left.\mu \mathrm{mol} / 100 \mathrm{~g} / \mathrm{min}\right)$ & $150.0 \pm 38.7$ & $198.5 \pm 36.7$ & $169.6 \pm 7.5$ & $236.9 \pm 8.9$ & 0.0099 & $<0.0001$ \\
\hline $\mathrm{CMRO}_{2}-\mathrm{Bush}(\mu \mathrm{mol} / 100 \mathrm{~g} / \mathrm{min})$ & $157.3 \pm 37.8$ & $203.9 \pm 31.9$ & $179.1 \pm 8.2$ & $236.9 \pm 8.9$ & 0.0097 & 0.00070 \\
\hline $\mathrm{CMRO}_{2}-\mathrm{Li}(\mu \mathrm{mol} / 100 \mathrm{~g} / \mathrm{min})$ & $136.8 \pm 42.9$ & $179.9 \pm 33.1$ & $153.9 \pm 5.5$ & $214.5 \pm 9.4$ & 0.028 & 0.00034 \\
\hline $\mathrm{CMRO}_{2}$-Bovine $(\mu \mathrm{mol} / 100 \mathrm{~g} / \mathrm{min})$ & $253.2 \pm 49.1$ & $193.6 \pm 22.9$ & $176.7 \pm 9.8$ & $216.2 \pm 36.8$ & 0.0073 & 0.0037 \\
\hline
\end{tabular}



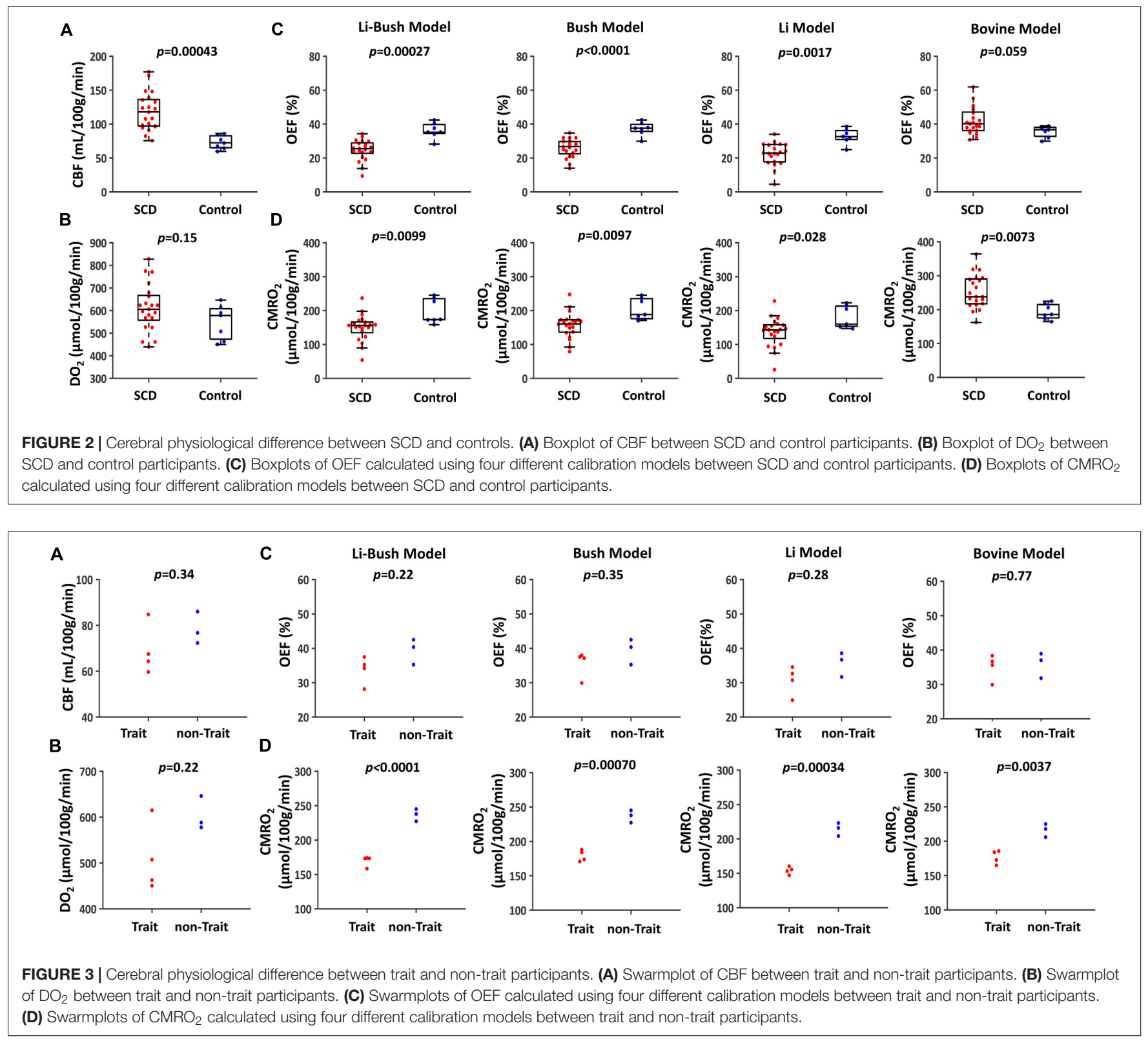

compared with controls, while the bovine model showed the opposite results. Importantly, we found that the relationship between sickle cell trait controls and non-trait controls is not dependent on model used, and $\mathrm{CMRO}_{2}$ was significantly lower in the trait participants regardless the model used.

$\mathrm{T}_{2}$-based MR oximetry such as TRUST MRI has been exploited widely due to its non-invasive property, less model assumption, short scan time and high reproducibility ( $\mathrm{Lu}$ and Ge, 2008; Lu et al., 2012; Xu et al., 2012; Jiang et al., 2018, 2021). However, inconsistent results have been reported on whether OEF and $\mathrm{CMRO}_{2}$ are increased, decreased or unaffected in sickle cell disease (Jordan et al., 2016; Bush et al., 2018b, 2021; Juttukonda et al., 2019, 2020; Li et al., 2020; Václavů et al., 2020; Prussien et al., 2021; Vu et al., 2021). Although one cannot rule out the possibility that different SCD population across different studies or other technical aspects such as different CBF measurement techniques may affect the results, the differences can be partly attributed to the $\mathrm{T}_{2}$-oxygenation calibration model used in the OEF quantification: Bush et al. (2018b), Juttukonda et al. (2020), Václavů et al. (2020), and Vu et al. (2021) used the Bush model, and consistently showed a decreased OEF and $\mathrm{CMRO}_{2}$ in patients with SCD; Li et al. (2020) reported the Li model and showed no change in both OEF and $\mathrm{CMRO}_{2}$; Bush et al. (2021) reported the joint Li-Bush model but did not report comparison with healthy controls; Jordan et al. (2016) and Juttukonda et al. (2019) used bovine model and both reported increased OEF and $\mathrm{CMRO}_{2}$ in more diseased people; Prussien et al. (2021) used human HbAA model presented in Bush et al. (2017) and showed that increased OEF was associated with deficits in executive function in SCD. 
TABLE 3 | Linear regression model results between cerebral physiology and hematological measures (entire cohort).

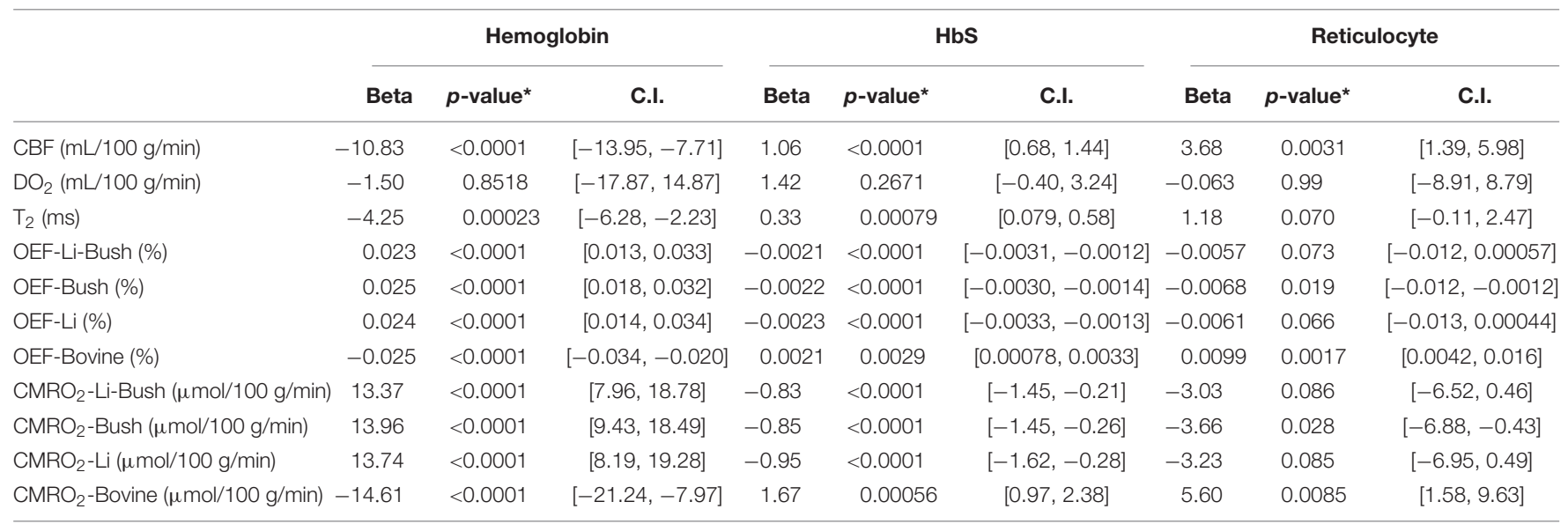

${ }^{*}$ Adjusted for age and sex.
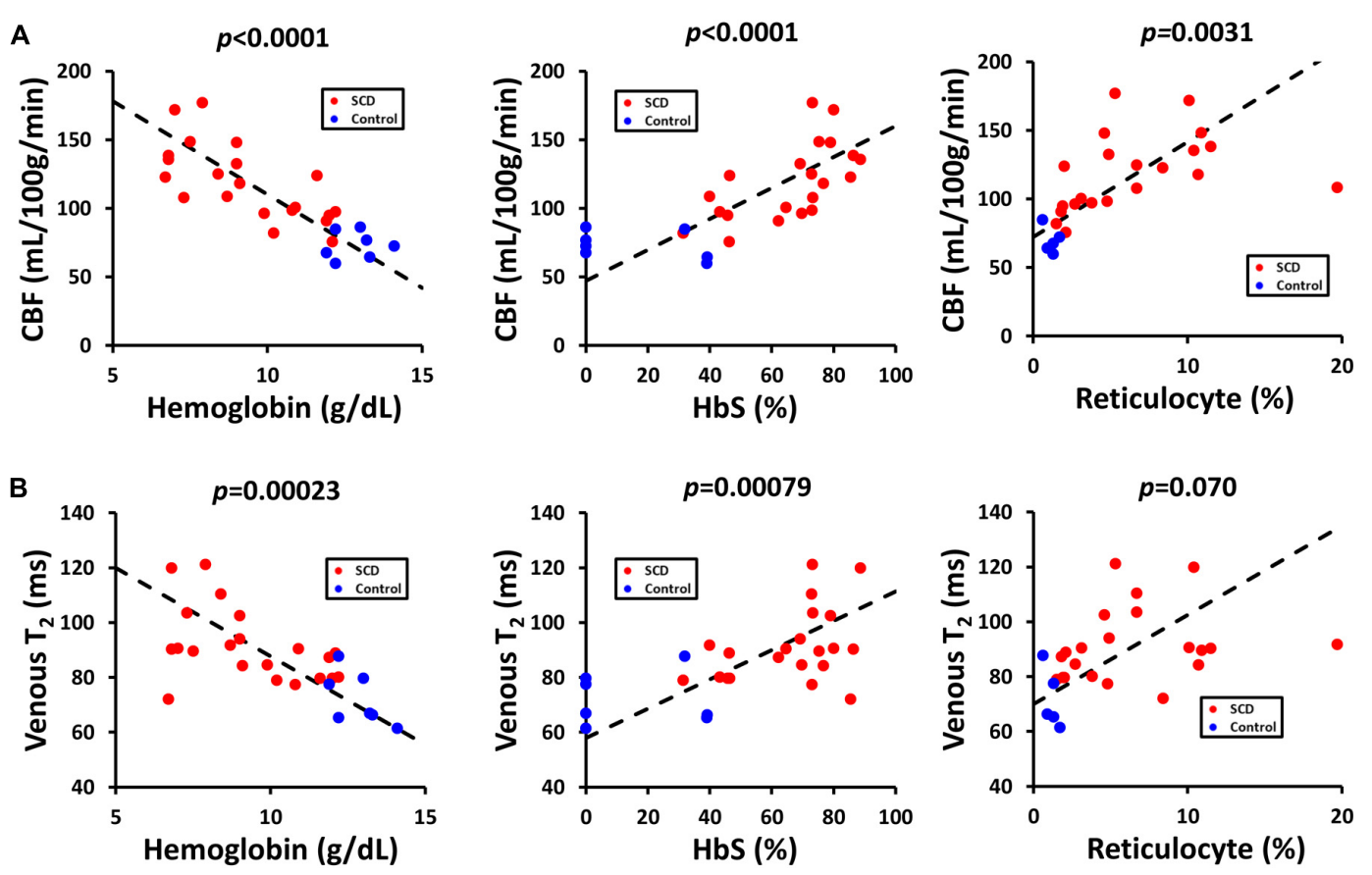

FIGURE 4 | Relationships between CBF, venous $\mathrm{T}_{2}$, and hematological measures. (A) Scatterplots between CBF and hemoglobin, $\mathrm{HbS}$ and reticulocyte level. (B) Scatterplots between venous $\mathrm{T}_{2}$ and hemoglobin, $\mathrm{HbS}$ and reticulocyte level.

The original bovine model was derived from bovine blood, which is thought to have similar magnetic properties as normal human blood (Lu et al., 2012). However, it was also speculated that the bovine model was calibrated in a relatively small hematocrit range (35-55\%), which is much higher than the hematocrit level in SCD (Lu et al., 2012; Bush et al., 2018b). In addition, the sickled red blood cell has different cell shape, size, permeability and tend to aggregate, which will affect the $\mathrm{T}_{2}$-relaxation in a different way than normal blood (Clark and Rossi, 1990; Gibson and Ellory, 2002). The higher concentration of reticulocytes and $\mathrm{HbF}$ could also alter the magnetic property of the sickled blood (Feng et al., 2015; Liu et al., 2016).
Three sickle-specific models have been presented recently, the Bush HbS model, the Li HbS model and the joint LiBush model (Bush et al., 2018b, 2021; Li et al., 2020). The advantage of these models is that they were directly calibrated using human sickled blood. However, these models also have the potential bias caused by the polymerization and cell lysing in the ex vivo studies, which may amplify the effect of sickled red blood cell on the $T_{2}-Y_{v}$ relationship. It should be mentioned that the Bush study was also conducted with a relatively narrow hematocrit range ( $28 \pm 4 \%$ ), and the resulting model did not have hematocrit dependence. Additionally, it should be pointed out that there are two important differences between the $T_{2}$ reported 

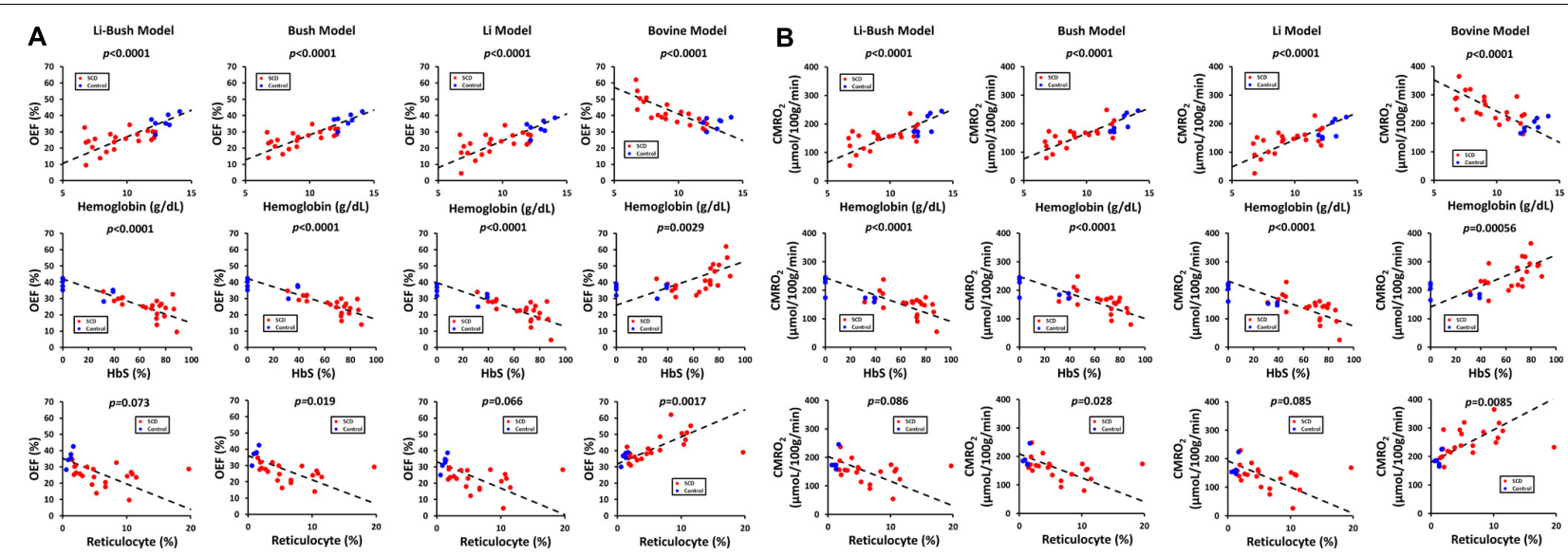

FIGURE 5 | Relationship between OEF, $\mathrm{CMRO}_{2}$, and hematological measures. (A) Scatterplots between OEF from different models and hemoglobin, HbS and reticulocyte level. (B) Scatterplots between $\mathrm{CMRO}_{2}$ from different models and hemoglobin, $\mathrm{HbS}$ and reticulocyte level.

TABLE 4 | Linear regression model results between cerebral physiology and hematological measures (within SCD participants).

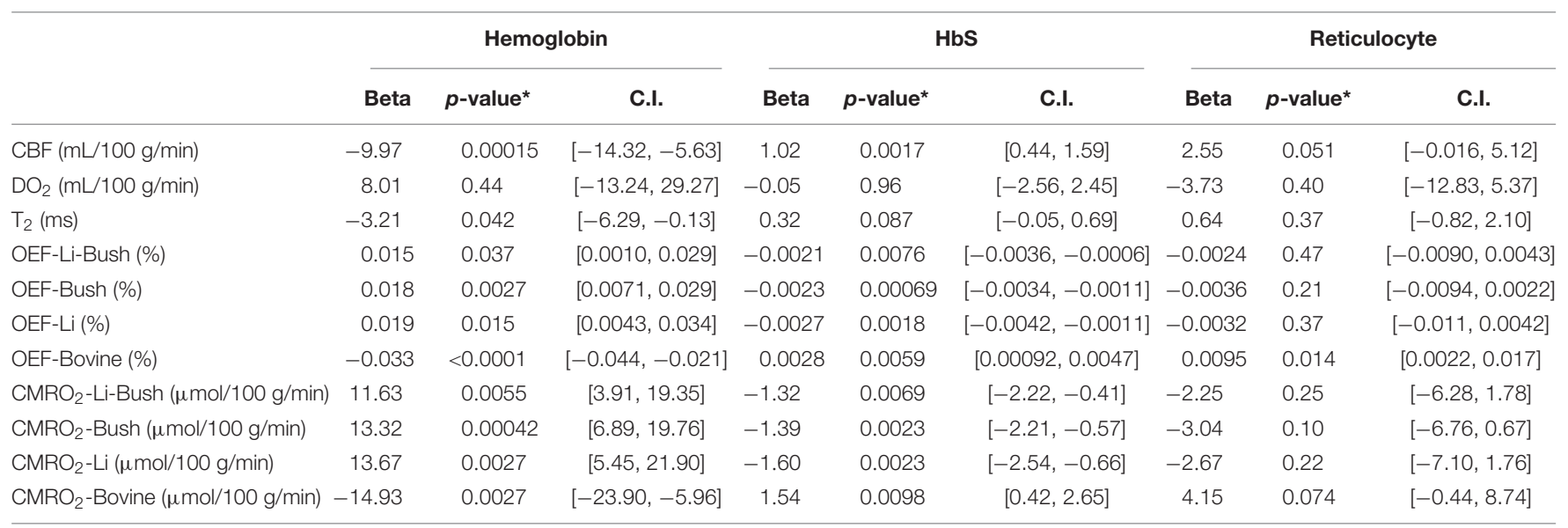

${ }^{*}$ Adjusted for age and sex.

in Li et al. (2020) and those reported using the TRUST sequence, i.e., those reported in Jordan et al. (2016) and Bush et al. (2018b). One is that $\mathrm{T}_{2}$ reported in Li et al. (2020) used a turbo field echo (TFE) acquisition, and this TFE- $\mathrm{T}_{2}$ is known to be systematically different from the standard $\mathrm{T}_{2}$ in that peripheral $\mathrm{k}$ lines in TFE $\mathrm{T}_{2}$ acquisition are under-estimated. In fact, a previous study has developed a correction method for TFE- $\mathrm{T}_{2}$ and showed that TFE$\mathrm{T}_{2}$ contains under-estimation for $\mathrm{T}_{2}$ values that are typical in SCD patients (Jiang et al., 2019). A second point is that, in $\mathrm{Li}$ et al. (2020) the in vivo $\mathrm{T}_{2}$ and the in vitro calibration $\mathrm{T}_{2}$ were not entirely equivalent. Their in vivo $\mathrm{T}_{2}$ was acquired on flowing blood, thus the TFE effect on the blood spin magnetization is different from the effect on the stationary blood. The stationary blood, which has no inflow spin refreshing, suffers from a greater TFE saturation effect in peripheral $\mathrm{k}$ lines. They reported a relative low $\mathrm{T}_{2}$ value for SCD participants $(60 \pm 10 \mathrm{~ms})$, lower than the $91.2 \mathrm{~ms}$ in the current study, $96.9 \mathrm{~ms}$ in Bush study, $77.5 \mathrm{~ms}$ in Jordan et al. (2016) and $88 \mathrm{~ms}$ in Václavů et al. (2020). Combining data from these two studies with different $\mathrm{T}_{2}$ measurements added more complexity to the problem. Also, the Bush model and Li-Bush model omitted the linear term compared with the original bovine model.

In this study, we tried to compare all four models within the same cohort. We also used individual HbS level to interpolate the sickled calibration plot and normal calibration plot to obtain the $\mathrm{Y}_{v}$ at an individual level, in order to consider the intersubject difference in terms of their blood composition. Our results showed decreased $\mathrm{OEF}$ and $\mathrm{CMRO}_{2}$ in $\mathrm{SCD}$ patients using Li-Bush model, Bush model, and the Li-model, but increased OEF and $\mathrm{CMRO}_{2}$ when using the bovine model. In general, our results are consistent with previous studies when using the same calibration models. The differences between the bovine model and the other three models are major and could result in completely opposite conclusions. The differences among the remaining three models are relatively small. These findings suggest that the disagreement in previous findings was partly attributed to the calibration model.

Li et al. (2020) reported a much closer OEF values (38\%) to the PET study (42-44\%) (Herold et al., 1986) compared with the Bush study (24\%). However, this could be largely attributed to the 
$\mathrm{T}_{2}$ measurement difference rather than the model difference (that is, $\mathrm{T}_{2}$ experimental measurement resulted in an over-estimation of OEF and the calibration model resulted in an under-estimation of OEF; and the combination of these two yielded OEF that are close to the expected values). In this study, we applied three $\mathrm{HbS}$ models on the same $\mathrm{T}_{2}$ values, and the estimated OEF were in the same range, suggesting that the Bush model and Li model do not differ too much.

Without a gold standard measure (e.g., direct blood sampling from jugular veins), it is not possible to definitely determine which model results reflect the actual true physiology. However, using the results of comparison between trait and non-trait controls, one may gain some insight on the plausibility of the findings. We emphasize that trait controls were found to have a lower $\mathrm{CMRO}_{2}$ compared to non-trait controls for all four models. Since trait participants are expected to manifest a milder degree of sickle cell pathophysiology, it is reasonable to speculate that SCD patients should also have a lower $\mathrm{CMRO}_{2}$. These notions support the use of a sickle-specific calibration models in SCD $\mathrm{T}_{2}$ $\mathrm{Y}_{v}$ conversion, however, all three of the existing models have their own limitations as stated above. Furthermore, in vitro calibration experiment in sickle cell blood may suffer from cell lysis during oxygenation maneuver or other biochemical changes (e.g., accumulation of methemoglobin). Thus, we propose that an ideal calibration method for SCD OEF estimation would be to conduct calibration in vivo on a subject-specific fashion. This could be conducted by performing blood $\mathrm{T}_{2}$ measurement in a superficial vein in the arm, followed by venous blood sampling to measure the oxygenation level. A two-point calibration could be achieved by adding arm compression to restrict blood flow (which will alter blood oxygenation) or applying hyperoxia inhalation. These studies should be considered in future investigations. We would like to emphasize that due to small group size, the statistical results for the comparisons between trait and non-trait groups in this study should be interpreted with caution. This observation should be viewed as a preliminary finding only, and its value is to point out a potential direction for future research to verify in a larger cohort.

The lower OEF and $\mathrm{CMRO}_{2}$ found in patients with lower hemoglobin using the sickle-specific models is consistent with a previous study using nitrous oxide method, which showed reduced cerebral arterio-venous oxygen difference and $\mathrm{CMRO}_{2}$ in SCD patients (Heyman et al., 1952). Another PET study reported no significant difference in $\mathrm{OEF}$ and $\mathrm{CMRO}_{2}$ between groups, but the authors attributed it to a small sample size (Herold et al., 1986). One possibility of the reduced OEF and $\mathrm{CMRO}_{2}$ is that the high flow velocity drives down the oxygen extraction ability, which leads to the diminished oxygen metabolism. The mismatch between increased CBF and decreased OEF could be due to decreased capillary transit time (Juttukonda et al., 2020) or excessive CBF (Bush et al., 2018b) in arteriovenous shunting. On the other hand, overt stroke and SCI are often reported in SCD patients (Miller et al., 2001; Prengler et al., 2002). The decreased oxygen metabolism could also be a protective mechanism, which decreases the energy need in order to avoid significant loss of energy supply in the situation of ischemia. In this study, we did not find a significant cognitive impairment in SCD participants, despite the observation of a potential $\mathrm{CMRO}_{2}$ difference. It may be that brain functional measures such as CMRO2 are more sensitive than neuropsychological tests in terms of detecting early brain abnormalities. Follow-up studies would provide more insight into the neurodevelopmental consequences of the oxygen metabolism impairment.

To our knowledge, there are few studies examining the oxygen metabolism in pediatric SCD patients. Existing studies on pediatric patients all used susceptometry-based method and reported incongruent results, i.e., increased or decreased OEF and $\mathrm{CMRO}_{2}$ (Fields et al., 2015, 2018; Croal et al., 2019), which may be related to the model assumption in the technique. In terms of magnetic susceptibility properties of SCD blood, one recent study systematically investigated the susceptibility difference between deoxy- and oxyhemoglobin, suggesting that $\mathrm{HbS}$ and $\mathrm{HbA}$ blood may have little differences in their susceptibilities (Eldeniz et al., 2021). Our study is the first to apply the $\mathrm{T}_{2}$-based oximetry on pediatric patients and confirmed a similar change of OEF and $\mathrm{CMRO}_{2}$ in SCD children compared with adults.

There are several limitations in our study. First, the sample size is relatively small and the study population is heterogeneous. Although the heterogeneity may make the comparison between SCD and control more complex, it could add more dynamic range of the parameters and provide more insight into the disease, rather than just focus on the most severe type. Considering the small sample size, it is hard to investigate how cerebral physiology is different for different phenotypes. More comprehensive studies with larger sample size would help to further understand the oxygen homeostasis in pediatric sickle cell disease. Second, the sickle-specific models are calibrated in adult HbS blood, which may be different than that of the pediatric population, considering different concentrations of $\mathrm{HbS}, \mathrm{HbF}$ and reticulocytes. For example, Liu et al. (2016) reported that neonatal blood has a longer $\mathrm{T}_{1}$ and $\mathrm{T}_{2}$ compared with adult blood at the same hematocrit and oxygenation level, potentially due to different molecular structure and oxygen biding affinity of $\mathrm{HbF}$. On the other hand, higher concentration of reticulocytes which has high molecular weight micro-organelles such as ribosomes could shorten the blood $\mathrm{T}_{2}$ (Feng et al., 2015). Thus the adult $\mathrm{HbS}$ model may not be suitable for pediatric population. Further studies may be needed to better establish the $\mathrm{T}_{2}$ calibration model in pediatric patients. Third, the TRUST MRI is a global measurement, which cannot provide regional information of the oxygen extraction. Future application of regional specific method may be useful.

\section{CONCLUSION}

We examined CBF, oxygen delivery, cerebral oxygen extraction, and metabolism in pediatric SCD patients. SCD patients revealed an elevated $\mathrm{CBF}$, but normal oxygen delivery. The results of OEF and $\mathrm{CMRO}_{2}$ were dependent on the calibration models used, and different models yielded opposite results. On the other hand, trait controls were found to have lower $\mathrm{CMRO}_{2}$ than non-trait 
controls, regardless of the model used, which may help shed some light on the model selection in SCD oxygenation studies.

\section{DATA AVAILABILITY STATEMENT}

The raw data supporting the conclusions of this article will be made available by the authors, without undue reservation.

\section{ETHICS STATEMENT}

The studies involving human participants were reviewed and approved by the Institutional Review Board (IRB) of Johns Hopkins University. Written informed consent to participate in this study was provided by the participants' legal guardian/next of kin.

\section{REFERENCES}

Berkelhammer, L. D., Williamson, A. L., Sanford, S. D., Dirksen, C. L., Sharp, W. G., Margulies, A. S., et al. (2007). Neurocognitive sequelae of pediatric sickle cell disease: a review of the literature. Child Neuropsychol. 13, 120-131. doi: 10.1080/09297040600800956

Bush, A., Borzage, M., Detterich, J., Kato, R. M., Meiselman, H. J., Coates, T., et al. (2017). Empirical model of human blood transverse relaxation at $3 \mathrm{~T}$ improves MRI T(2) oximetry. Magn. Reson. Med. 77, 2364-2371. doi: 10.1002/mrm. 26311

Bush, A., Chai, Y., Choi, S. Y., Vaclavu, L., Holland, S., Nederveen, A., et al. (2018a). Pseudo continuous arterial spin labeling quantification in anemic subjects with hyperemic cerebral blood flow. Magn. Reson. Imaging 47, 137-146. doi: 10. 1016/j.mri.2017.12.011

Bush, A. M., Coates, T. D., and Wood, J. C. (2018b). Diminished cerebral oxygen extraction and metabolic rate in sickle cell disease using $\mathrm{T} 2$ relaxation under spin tagging MRI. Magn. Reson. Med. 80, 294-303. doi: 10.1002/mrm.27015

Bush, A., Vu, C., Choi, S., Borzage, M., Miao, X., Li, W., et al. (2021). Calibration of T2 oximetry MRI for subjects with sickle cell disease. Magn. Reson. Med. 86, 1019-1028. doi: 10.1002/mrm.28757

Clark, M. R., and Rossi, M. E. (1990). Permeability characteristics of deoxygenated sickle cells. Blood 76, 2139-2145.

Croal, P. L., Leung, J., Phillips, C. L., Serafin, M. G., and Kassner, A. (2019). Quantification of pathophysiological alterations in venous oxygen saturation: a comparison of global MR susceptometry techniques. Magn. Reson. Imaging 58, 18-23. doi: 10.1016/j.mri.2019.01.008

Eldeniz, C., Binkley, M. M., Fields, M., Guilliams, K., Ragan, D. K., Chen, Y., et al. (2021). Bulk volume susceptibility difference between deoxyhemoglobin and oxyhemoglobin for HbA and HbS: a comparative study. Magn. Reson. Med. 85, 3383-3393. doi: $10.1002 / \mathrm{mrm} .28668$

Feng, Y., Taraban, M. B., and Yu, Y. B. (2015). Water proton NMR-a sensitive probe for solute association. Chem. Commun. 51, 6804-6807. doi: 10.1039/ C5CC00741K

Fields, M. E., Guilliams, K. P., Ragan, D., Eldeniz, C., Binkley, M., Hulbert, M. L., et al. (2015). Elevations in MR Measurements of Whole Brain and Regional Cerebral Blood Flow and Oxygen Extraction Fraction Suggest Cerebral Metabolic Stress in Children with Sickle Cell Disease Unaffected By Overt Stroke. Blood 126, 69-69. doi: 10.1182/blood.V126.23.69.69

Fields, M. E., Guilliams, K. P., Ragan, D. K., Binkley, M. M., Eldeniz, C., Chen, Y., et al. (2018). Regional oxygen extraction predicts border zone vulnerability to stroke in sickle cell disease. Neurology 90, e1134-e1142. doi: 10.1212/WNL. 0000000000005194

Gibson, J. S., and Ellory, J. C. (2002). Membrane transport in sickle cell disease. Blood Cells Mol. Dis. 28, 303-314. doi: 10.1006/bcmd.2002.0515

Guilliams, K. P., Fields, M. E., Ragan, D. K., Eldeniz, C., Binkley, M. M., Chen, Y., et al. (2018). Red cell exchange transfusions lower cerebral blood flow and

\section{AUTHOR CONTRIBUTIONS}

ZL, JC, HL, and EL designed the research study and wrote the manuscript. ZL, PL, HL, and EL performed the MRI experiments and collected the data. TM, EL, and AC designed and/or performed the cognitive examination. ZL, TM, DJ, KS, and AT analyzed the data. JC assisted with the interpretation of data. All authors edited and approved the manuscript.

\section{FUNDING}

This work was supported by the National Institutes of Health (Nih) grant R01 Ag064792, Rf1 Ag071515, R01 Ns106711, R01 Ns106702, P41 Eb015909, P41 Eb031771, S10 Od021648, K23 Hl133455-01A1, U54 Hd079123, and P50 Hd103538.

oxygen extraction fraction in pediatric sickle cell anemia. Blood 131, 1012-1021. doi: 10.1182/blood-2017-06-789842

Guyton, A. C., and Hall, J. E. (2005). Textbook of Medical Physiology. Philadelphia (PA): Elsevier.

Herold, S., Brozovic, M., Gibbs, J., Lammertsma, A. A., Leenders, K. L., Carr, D., et al. (1986). Measurement of regional cerebral blood flow, blood volume and oxygen metabolism in patients with sickle cell disease using positron emission tomography. Stroke 17, 692-698. doi: 10.1161/01.str.17.4.692

Heyman, A., Patterson, J. L. Jr., and Duke, T. W. (1952). Cerebral Circulation And Metabolism In Sickle Cell And Other Chronic Anemias, With Observations On The Effects Of Oxygen Inhalation. J. Clin. Investig. 31, 824-828. doi: 10.1172/ JCI102668

Hurlet-Jensen, A. M., Prohovnik, I., Pavlakis, S. G., and Piomelli, S. (1994a). Effects of total hemoglobin and hemoglobin $\mathrm{S}$ concentration on cerebral blood flow during transfusion therapy to prevent stroke in sickle cell disease. Stroke 25, 1688-1692. doi: 10.1161/01.str.25.8.1688

Hurlet-Jensen, A. M., Prohovnik, I., Pavlakis, S. G., and Piomelli, S. (1994b). Effects of total hemoglobin and hemoglobin $S$ concentration on cerebral blood flow during transfusion therapy to prevent stroke in sickle cell disease. Stroke 25, 1688-1692. doi: 10.1161/01.STR.25.8.1688

Jacob, M., Saunders, D. E., Sangeda, R. Z., Ahmed, M., Tutuba, H., Kussaga, F., et al. (2020). Cerebral Infarcts and Vasculopathy in Tanzanian Children With Sickle Cell Anemia. Pediatr. Neurol. 107, 64-70. doi: 10.1016/j.pediatrneurol.2019.12. 008

Jiang, D., Deng, S., Franklin, C. G., O’Boyle, M., Zhang, W., Heyl, B. L., et al. (2021). Validation of T2-based oxygen extraction fraction measurement with 150 positron emission tomography. Magn. Reson. Med. 85, 290-297. doi: 10. $1002 / \mathrm{mrm} .28410$

Jiang, D., Liu, P., Li, Y., Mao, D., Xu, C., and Lu, H. (2018). Cross-vendor harmonization of T2-relaxation-under-spin-tagging (TRUST) MRI for the assessment of cerebral venous oxygenation. Magn. Reson. Med. 80, 1125-1131. doi: $10.1002 / \mathrm{mrm} .27080$

Jiang, D., Lu, H., Parkinson, C., Su, P., Wei, Z., Pan, L., et al. (2019). Vessel-specific quantification of neonatal cerebral venous oxygenation. Magn. Reson. Med. 82, 1129-1139. doi: 10.1002/mrm.27788

Jordan, L. C., and DeBaun, M. R. (2018). Cerebral hemodynamic assessment and neuroimaging across the lifespan in sickle cell disease. J. Cereb. Blood Flow Metab. 38, 1438-1448. doi: 10.1177/0271678X17701763

Jordan, L. C., Gindville, M. C., Scott, A. O., Juttukonda, M. R., Strother, M. K., Kassim, A. A., et al. (2016). Non-invasive imaging of oxygen extraction fraction in adults with sickle cell anaemia. Brain 139, 738-750. doi: 10.1093/brain/ awv397

Juttukonda, M. R., Donahue, M. J., Waddle, S. L., Davis, L. T., Lee, C. A., Patel, N. J., et al. (2020). Reduced oxygen extraction efficiency in sickle cell anemia patients with evidence of cerebral capillary shunting. J. Cereb. Blood Flow Metab. 41, 271678X20913123. doi: 10.1177/0271678X20913123 
Juttukonda, M. R., Jordan, L. C., Gindville, M. C., Davis, L. T., Watchmaker, J. M., Pruthi, S., et al. (2017). Cerebral hemodynamics and pseudo-continuous arterial spin labeling considerations in adults with sickle cell anemia. NMR Biomed. 30:e3681. doi: 10.1002/nbm.3681

Juttukonda, M. R., Lee, C. A., Patel, N. J., Davis, L. T., Waddle, S. L., Gindville, M. C., et al. (2019). Differential cerebral hemometabolic responses to blood transfusions in adults and children with sickle cell anemia. J. Magn. Reson. Imaging 49, 466-477. doi: 10.1002/jmri.26213

Kety, S. S., and Schmidt, C. F. (1948). The Effects Of Altered Arterial Tensions Of Carbon Dioxide And Oxygen On Cerebral Blood Flow And Cerebral Oxygen Consumption Of Normal Young Men. J. Clin. Investig. 27, 484-492. doi: 10. 1172/JCI101995

Kirkham, F. J., and Lagunju, I. A. (2021). Epidemiology of Stroke in Sickle Cell Disease. J. Clin. Med. 10, 4232. doi: 10.3390/jcm10184232

Lance, E. I., Cannon, A. D., Shapiro, B. K., Lee, L.-C., Johnston, M. V., and Casella, J. F. (2021). Co-Occurrence of Neurodevelopmental Disorders in Pediatric Sickle Cell Disease. J. Dev. Behav. Pediatr. 42, 463-471. doi: 10.1097/DBP. 0000000000000914

Lance, E. I., Comi, A. M., Johnston, M. V., Casella, J. F., and Shapiro, B. K. (2015). Risk Factors for Attention and Behavioral Issues in Pediatric Sickle Cell Disease. Clin. Pediatr. 54, 1087-1093. doi: 10.1177/000992281559 4356

Leung, J., Duffin, J., Fisher, J. A., and Kassner, A. (2016). MRI-based cerebrovascular reactivity using transfer function analysis reveals temporal group differences between patients with sickle cell disease and healthy controls. NeuroImage Clin. 12, 624-630. doi: 10.1016/j.nicl.2016. 09.009

Li, W., Xu, X., Liu, P., Strouse, J. J., Casella, J. F., Lu, H., et al. (2020). Quantification of whole-brain oxygenation extraction fraction and cerebral metabolic rate of oxygen consumption in adults with sickle cell anemia using individual T2 based oxygenation calibrations. Magn. Reson. Med. 83, 1066-1080. doi: 10.1002/ mrm. 27972

Liu, P., Chalak, L. F., Krishnamurthy, L. C., Mir, I., Peng, S. L., Huang, H., et al. (2016). T1 and T2 values of human neonatal blood at 3 Tesla: dependence on hematocrit, oxygenation, and temperature. Magn. Reson. Med. 75, 1730-1735. doi: $10.1002 / \mathrm{mrm} .25775$

$\mathrm{Lu}, \mathrm{H}$., and Ge, Y. (2008). Quantitative evaluation of oxygenation in venous vessels using T2-Relaxation-Under-Spin-Tagging MRI. Magn. Reson. Med. 60, 357-363. doi: $10.1002 / \mathrm{mrm} .21627$

Lu, H., Xu, F., Grgac, K., Liu, P., Qin, Q., and van Zijl, P. (2012). Calibration and validation of TRUST MRI for the estimation of cerebral blood oxygenation. Magn. Reson. Med. 67, 42-49. doi: 10.1002/mrm.22970

Miller, S. T., Macklin, E. A., Pegelow, C. H., Kinney, T. R., Sleeper, L. A., Bello, J. A., et al. (2001). Silent infarction as a risk factor for overt stroke in children with sickle cell anemia: a report from the Cooperative Study of Sickle Cell Disease. J. Pediatr. 139, 385-390. doi: 10.1067/mpd.2001.117580

Mori, S., Wu, D., Ceritoglu, C., Li, Y., Kolasny, A., Vaillant, M. A., et al. (2016). MRICloud: delivering High-Throughput MRI Neuroinformatics as CloudBased Software as a Service. Comput. Sci. Eng. 18, 21-35. doi: 10.1109/MCSE. 2016.93

Morris, E. A., Juttukonda, M. R., Lee, C. A., Patel, N. J., Pruthi, S., Donahue, M. J., et al. (2018). Elevated brain oxygen extraction fraction in preterm newborns with anemia measured using noninvasive MRI. J. Perinatol. 38, 1636-1643. doi: 10.1038/s41372-018-0229-1

Pauling, L., Itano, H. A., Singer, S. J., and Wells, I. C. (1949). Sickle cell anemia, a molecular disease. Science 110, 543-548.

Peng, S. L., Dumas, J. A., Park, D. C., Liu, P., Filbey, F. M., McAdams, C. J., et al. (2014). Age-related increase of resting metabolic rate in the human brain. Neuroimage 98, 176-183. doi: 10.1016/j.neuroimage.2014.04.078

Peng, S. L., Su, P., Wang, F. N., Cao, Y., Zhang, R., Lu, H., et al. (2015). Optimization of phase-contrast MRI for the quantification of whole-brain cerebral blood flow. J. Magn. Reson. Imaging 42, 1126-1133. doi: 10.1002/jmri. 24866
Prengler, M., Pavlakis, S. G., Prohovnik, I., and Adams, R. J. (2002). Sickle cell disease: the neurological complications. Ann. Neurol. 51, 543-552. doi: 10.1002/ ana. 10192

Prussien, K. V., Compas, B. E., Siciliano, R. E., Ciriegio, A. E., Lee, C. A., Kassim, A. A., et al. (2021). Cerebral Hemodynamics and Executive Function in Sickle Cell Anemia. Stroke 52, 1830-1834. doi: 10.1161/STROKEAHA.120.032741

Silvennoinen, M. J., Clingman, C. S., Golay, X., Kauppinen, R. A., and van Zijl, P. C. M. (2003). Comparison of the dependence of blood R2 and R on oxygen saturation at 1.5 and 4.7 Tesla. Magn. Reson. Med. 49, 47-60. doi: 10.1002/mrm. 10355

Stotesbury, H., Kawadler, J. M., Saunders, D. E., and Kirkham, F. J. (2021). MRI detection of brain abnormality in sickle cell disease. Expert Rev. Hematol. 14, 473-491. doi: 10.1080/17474086.2021.1893687

Switzer, J. A., Hess, D. C., Nichols, F. T., and Adams, R. J. (2006). Pathophysiology and treatment of stroke in sickle-cell disease: present and future. Lancet Neurol. 5, 501-512. doi: 10.1016/S1474-4422(06)70469-0

Václavů, L., Meynart, B. N., Mutsaerts, H. J. M. M., Petersen, E. T., Majoie, C. B. L. M., VanBavel, E., et al. (2019). Hemodynamic provocation with acetazolamide shows impaired cerebrovascular reserve in adults with sickle cell disease. Haematologica 104, 690-699. doi: 10.3324/haematol.2018.206094

Vaclavu, L., Petersen, E. T., VanBavel, E. T., Majoie, C. B. L., Nederveen, A. J., and Biemond, B. J. (2018). Reduced Cerebral Metabolic Rate of Oxygen in Adults with Sickle Cell Disease. Blood 132:11. doi: 10.1182/blood-2018-99-116194

Václavů, L., Petr, J., Petersen, E. T., Mutsaerts, H. J. M. M., Majoie, C. B. L., Wood, J. C., et al. (2020). Cerebral oxygen metabolism in adults with sickle cell disease. Am. J. Hematol. 95, 401-412. doi: 10.1002/ajh.25727

Vu, C., Bush, A., Choi, S., Borzage, M., Miao, X., Nederveen, A. J., et al. (2021). Reduced global cerebral oxygen metabolic rate in sickle cell disease and chronic anemias. Am. J. Hematol. 96, 901-913. doi: 10.1002/ajh.26203

Wright, G. A., Hu, B. S., and Macovski, A. (1991). Estimating oxygen saturation of blood in vivo with MR imaging at 1.5 T. J. Magn. Reson. Imaging 1, 275-283. doi: $10.1002 /$ jmri.1880010303

$\mathrm{Xu}, \mathrm{F}$., Uh, J., Liu, P., and Lu, H. (2012). On improving the speed and reliability of T2-relaxation-under-spin-tagging (TRUST) MRI. Magn. Reson. Med. 68, 198-204. doi: 10.1002/mrm.23207

Zhao, J. M., Clingman, C. S., Närväinen, M. J., Kauppinen, R. A., and van Zijl, P. C. M. (2007). Oxygenation and hematocrit dependence of transverse relaxation rates of blood at 3T. Magn. Reson. Med. 58, 592-597. doi: 10.1002/ mrm. 21342

Conflict of Interest: EL served on an advisory board for Novartis for sickle cell disease therapeutics. JC is an inventor and a named party on a patent and licensing agreement to ImmunArray through Johns Hopkins for a panel of brain biomarkers for the detection of brain injury, and also holds a patent for aptamers as a potential treatment for sickle cell disease.

The remaining authors declare that the research was conducted in the absence of any commercial or financial relationships that could be construed as a potential conflict of interest.

Publisher's Note: All claims expressed in this article are solely those of the authors and do not necessarily represent those of their affiliated organizations, or those of the publisher, the editors and the reviewers. Any product that may be evaluated in this article, or claim that may be made by its manufacturer, is not guaranteed or endorsed by the publisher.

Copyright $\odot 2022$ Lin, McIntyre, Jiang, Cannon, Liu, Tekes, Casella, Slifer, Lu and Lance. This is an open-access article distributed under the terms of the Creative Commons Attribution License (CC BY). The use, distribution or reproduction in other forums is permitted, provided the original author(s) and the copyright owner(s) are credited and that the original publication in this journal is cited, in accordance with accepted academic practice. No use, distribution or reproduction is permitted which does not comply with these terms. 